\title{
Is Making Smoking Status a Vital Sign Sufficient to Increase Cessation Support Actions in Clinical Practice?
}

Raymond Boyle, $P b D$
Leif I. Solberg, $M D$

HealthPartners Research Foundation, Minneapolis, Minn
Conflicts of interest: none reported

\section{CORRESPONDING AUTHOR}

Raymond Boyle, $\mathrm{PhD}$

HealthPartners Research Foundation

8100 34th Ave South

PO Box 1524

Minneapolis, MN 55440-1524

raymond.boyle@healthpartners.com

\begin{abstract}
BACKGROUND There is widespread belief that adding smoking status to the list of vital signs in medical practice will lead to an increased likelihood that physicians will offer more cessation support for smokers during office visits. This article evaluates the impact of introducing routine use of smoking status as a vital sign on clinician cessation support in a primary care setting.
\end{abstract}

METHODS A total of 429 adult health plan members who were smokers and recent quitters from 2 primary care clinics in Minneapolis, Minn, were administered a 28-item questionnaire by telephone. The instrument included questions about patient health status, smoking status, advice about smoking, clinic actions during the most recent visit, satisfaction with clinic actions, and intention to change smoking. Comparisons were made with a cohort of smoking patients before and after smoking status was used as a vital sign, using 2-tailed $t$ tests for continuous variables and chi-square analysis for categorical variables.

RESULTS Patient self-report of receiving advice about smoking in the past year (about 66\%) was unchanged after smoking status was implemented as a vital sign. Medical chart documentation of tobacco use increased from $38.0 \%$ to $78.4 \%$ of all encounters, whereas documentation of advice about smoking decreased from $33.5 \%$ to $18.8 \%$. Except for identification of tobacco use before implementation of the guideline, none of the specific activities recommended in the guideline occurred at very high levels.

CONCLUSION Implementing smoking status as a vital sign appears to have increased the documentation of tobacco use but had little effect on specific implementation actions. Overall, the findings suggest that more consistent identification of tobacco use alone will not lead to guideline-recommended changes in cessation support actions by clinicians. Greater environmental changes will be needed if tobacco guideline goals are to be achieved.

Ann Fam Med 2004;2:22-25. DOI: 10.1370/afm.38.

\section{INTRODUCTION}

T The current Tobacco Use and Dependence Clinical Practice Guideline from the US Public Health Service (PHS) provides clear evidence that identification of smokers and providing support for smoking cessation in medical practice are effective.' The US Preventive Services Task Force also has placed a high priority on offering tobacco cessation support on a regular basis to all smoking patients. ${ }^{2}$ The goal of increasing physician advice about tobacco use is also found in the National Health Promotion and Disease Prevention objectives for the year 2000, ${ }^{3}$ where the objective is an advice rate of $75 \%$ among primary care and oral health care providers. Despite the evidence of efficacy and effectiveness for smoking cessation support, however, physicians still are not providing advice and assistance as often as desirable., ${ }^{4,5}$ 
A strategy for increasing the support rate for smoking cessation by health care providers was highlighted in 1991, when Fiore ${ }^{6}$ suggested that smoking status become a routine vital sign. Elevating smoking status to a vital sign serves to remind clinicians of the need to address smoking during office visits for any reason. This component of office systems has been seen as key to changing physician behavior. ${ }^{7}$ Although some studies have shown support for this idea, the results have been mixed. Recent research suggests that using chart reminders increases the proportion of physicians who ask and advise smoking patients. ${ }^{8-12}$ Other research suggests that the concept of smoking status as a vital sign has not yet caught on widely. . $^{, 13,14}$

We had an opportunity to study the effects of adding smoking status as a vital sign in 2 primary care clinics that implemented a smoking cessation guideline. Both clinics adopted a routine place to record tobacco use and smoking status during clinic visits. In addition, they assigned a lead person to coordinate implementation; however, no other systematic changes to supportcessation actions were taken.

\section{METHODS}

This study was conducted at HealthPartners, a mixed-model managed care organization serving 650,000 members in the metropolitan cities of Minneapolis and St. Paul. Adult members of HealthPartners attending 2 primary care clinics were surveyed in 1994 and formed the basis for this study. Clinic A was a staff model (owned) primary care clinic with 3,100 adult members served by 4 family physicians. Clinic B was a group practice of 10 family physicians serving 3,200 members of HealthPartners plus many other nonmembers.

\section{Preguideline Survey}

Adult members of HealthPartners attending these 2 clinics were surveyed as part of another study to examine behavioral risk factors. Of the combined 6,409 adult (older than 18 years) HealthPartners members who were enrolled at the 2 primary care clinics, 4,667 (73\%) were reached by telephone and agreed to participate in a 15- to 20-minute telephone survey to assess smoking status, physical activity, diet, and respondents' readiness to change these behaviors. Other data collected included age, sex, education, and use of preventive services. This database provided a vehicle to again contact patients who were smokers at these 2 clinics. A total of 647 smokers and 97 recent quitters $(\mathrm{N}=744)$ were identified from this baseline survey. The HealthPartners Research Foundation Institutional Review Board approved this study.

\section{Postguideline Survey}

Of the 744 members identified from the baseline survey, 138 were excluded from this study because they no longer belonged to HealthPartners $(n=117)$, they made no visits to the clinics $(n=11)$, their smoking status was misclassified $(\mathrm{n}=6)$, or they had died $(\mathrm{n}=$ 4), leaving 606 eligible subjects.

\section{Instrument}

The survey instrument was designed to measure the extent to which smokers and recent quitters received appropriate assessment and follow-up. A 28-item questionnaire was designed to be administered by telephone. This instrument included questions about patient health status, smoking status, advice about smoking, clinic actions during the most recent visit, satisfaction with clinic actions, and intention to change smoking. Completed questionnaires were obtained from 429 subjects; adjusting for the excluded members yielded a response rate of $70.8 \%$ (429 of 606). A decision was made to limit the analysis to respondents who reported a clinic visit within the 12 months before the time of the survey so that they could report on clinic actions during that period. Because 97 (22.6\%) members had no visit in the previous year, data reported here are based on the 332 respondents who reported at least 1 visit during the previous 12 months.

\section{Chart Review}

At the time of the postguideline survey, permission was obtained for an audit of the respondent's medical chart to ascertain the documentation of clinic actions about smoking. Of the 429 respondents who were asked, $79 \%$ (338) granted permission to provide consent for a review of their medical record. Patient medical charts were examined for a 16 -month period before and after the guideline was implemented. This postguideline period included the full implementation start date in both clinics and the completion of the postguideline survey. A chart review form was created, underwent a pilot test, and was modified based on this testing. Tobacco use documentation was recorded as unknown or no documentation, nonuser, or current smoker. Evidence of support actions for current smokers also was recorded as a series of yes-no options. The final instrument, consisting of a 1 -page form, was used to review charts by a single auditor who was experienced with reviewing medical charts. Intrarater reliability was assessed using a random sample of 20 charts from each clinic for a second review. A total of 94 encounters were recorded in these 20 charts, and the level of agreement was $92.5 \%$ between the first and second reviews of these encounters. 


\section{Analysis}

Analysis of numerical data was carried out using SPSS Before and after comparisons were made using 2-tailed $t$ tests for continuous variables and chi-square analysis for categorical variables. The analysis of encounters was adjusted at the individual level for the number of encounters. Each patient visit was treated as an observation for the analysis; however, these observations were weighted by the inverse of the number of visits for each respondent, both before and after the guideline was implemented. As a result, each respondent contributed an equal amount of information toward the analysis, regardless of how many times that patient had a clinic visit.

\section{RESULTS}

The baseline characteristics of the respondents across the 2 clinics are displayed in Table 1 . The respondents in the staff model clinic were older, but there were no other differences. Compared with the preguideline period, we found no difference at follow-up in the proportion of smokers reporting advice to quit smoking after the guideline was implemented ( $66.3 \%$ vs $66.5 \%)$.

\section{Table 1. Baseline Characteristics of Smokers from 2 Clinics $(\mathrm{N}=332)$}

\begin{tabular}{lcc}
\hline Characteristics & $\begin{array}{c}\text { Owned Clinic } \\
\text { ( } \mathbf{n}=\mathbf{1 8 8})\end{array}$ & $\begin{array}{c}\text { Contract Clinic } \\
\text { (n = 144) }\end{array}$ \\
\hline Sex (\% female) & 55 & 61 \\
Age (mean; years) & 45 & $41^{*}$ \\
Marital status (\% married) & 72.2 & 65.4 \\
Education (\% > high school) & 53.4 & 52.1 \\
Health excellent or very good & 62.5 & 59 \\
Advised to quit smoking in & 56 & 60 \\
$\quad$ last year & & 68.4 \\
Satisfied or very satisfied with & 67.0 & \\
clinic help to quit smoking & \multicolumn{2}{l}{} \\
\hline *P < .025; all other comparisons are not statistically significant.
\end{tabular}

Table 2. Comparison of Clinic Actions Before and After Implementation of Smoking Status as a Vital Sign

\begin{tabular}{lcccccc}
\hline & \multicolumn{2}{c}{ Owned Clinic } & \multicolumn{2}{c}{ Contract Clinic } & \multicolumn{2}{c}{ Overall } \\
\cline { 2 - 7 } Clinic Action & $\begin{array}{c}\text { Baseline } \\
\mathbf{( \% )}\end{array}$ & $\begin{array}{c}\text { Change } \\
\mathbf{( \% )}\end{array}$ & $\begin{array}{c}\text { Baseline } \\
\mathbf{( \% )}\end{array}$ & $\begin{array}{c}\text { Change } \\
\mathbf{( \% )}\end{array}$ & $\begin{array}{c}\text { Baseline } \\
\mathbf{( \% )}\end{array}$ & $\begin{array}{c}\text { Change } \\
\mathbf{( \% )}\end{array}$ \\
\hline Documented tobacco use & 41.5 & +30.5 & 31.8 & +55.8 & 38.0 & +40.0 \\
Assessed interest in quitting & 21.3 & -10.8 & 31.5 & -1.6 & 24.1 & -4.7 \\
Quit date discussion & 4.0 & -2.0 & 1.8 & -1.8 & 3.3 & -2.0 \\
Advised to quit & 28.7 & -10.9 & 44.8 & -25.0 & 33.5 & -16.0 \\
Written information provided & 4.6 & +6.6 & 0.0 & +6.8 & 3.2 & +6.0 \\
NRT discussion & 10.8 & -6.2 & 20.6 & -17.3 & 14.0 & -9.7 \\
\hline NRT = nicotine replacement therapy & & & & & & \\
\hline
\end{tabular}

\section{Preguideline Audit}

A total of 1,057 encounters were documented across both clinics during the preguideline period, and 281 members had at least 1 visit. The number of encounters ranged from 1 to 13 , with a mean of $3.8(\mathrm{SD}=2.6)$ and a median of 3.0. Overall tobacco use was documented in $38 \%$ of encounters. Interest in quitting was assessed among smokers in $24.1 \%$ of encounters, with no difference between clinics. Evidence of smoking patients being advised to quit smoking was found in $33.5 \%$ of encounters, whereas discussion of a quit date with smokers was documented in only $3.3 \%$ of encounters.

\section{Postguideline Audit}

A total of 795 encounters were examined during the postguideline period, and 227 members had at least 1 visit documented in the chart during this time. The number of encounters ranged from 1 to 19 , with a mean of $3.5(\mathrm{SD}=3.0)$ and a median of 3.0. More than a quarter of participants $(28.6 \%)$ had only 1 encounter, and another $21 \%$ had 2 encounters. Tobacco use was documented in $78.4 \%$ of encounters, and clinic B was significantly more likely to have documented tobacco use than clinic A $(87.6 \%$ vs $72 \%, P<.005)$. An increase (38\% vs $78.4 \%$ ) in documenting tobacco use observed between the audit periods $(P<.01)$ was the only significant change in clinical activity after tobacco use was implemented as a routine vital sign (Table 2 ).

\section{DISCUSSION}

The clinical practice guideline for tobacco recommended stepped delivery of care from determination of tobacco use at nearly every primary care clinic visit to delivery of appropriate assistance and follow-up for smokers who are receptive to quitting smoking. Although this study showed a striking increase in the documentation of tobacco use, rates of advice to quit smoking, as well as other cessation support activities, did not improve. The results of this study suggest that the using smoking status as a vital sign is not sufficient to effect change in clinician behavior. At least in these 2 clinics, marked increase in the identification of smokers as a first step did not necessarily lead to further smoking advice, counseling, or follow-up.

One limitation of this study is that the smoking advice rates 
reported by smokers in this study (66\%) are higher than are usually reported, ranging from $37 \%$ to $46 \%{ }^{15-17}$ We also recognize that there are some problems with the methods of assessing clinician smoking-cessation activities. For example, it has been documented that smokers tend to overestimate these actions, at least if they occurred recently. ${ }^{18,19}$ On the other hand, chart audits clearly underestimate counseling actions, so the correct answers are probably somewhere between results obtained by these 2 methods. In addition, all the patients studied were relatively long-term members of a single health plan (HealthPartners). Thus, any difference in the reports or experiences of other types of patients could affect the results.

The main finding from this study is that determining a patient's smoking status might be a necessary firststep component of implementing a smoking cessation system in clinical practice, but it does not necessarily lead to further smoking counseling, advice, or followup. Overall, the findings reinforce previous research suggesting that calling attention to desired clinical actions will not change clinician behavior if there are no strong environmental changes that make new behavior easier to comply with than to avoid. ${ }^{20-22}$ Clearly, more comprehensive systems changes are needed.

To read commentaries or to post a response to this article, see it online at http://www.annfammed.org/cgi/content/full/2/1/22.

Submitted November 2, 2002; submitted, revised, February 13, 2003; accepted February 17, 2003.

Key words: Signs and symptoms; clinical practice patterns; physician's practice patterns; smoking; smoking cessation

Funding support: This study was supported by a grant from the Institute for Clinical Systems Improvement.

Acknowledgments: The preparation of this article was made possible by the contributions of staff at HealthPartners Research Foundation, including Kirsten Hase, Brita Hedblom, Jerry Amundson, William Rush, and Carol Westrum.

\section{References}

1. Surgeon General. Reducing the Health Consequences of Smoking: 25 years of Progress. A Report of the Surgeon General. Washington, DC: US Dept of Health and Human Services; 1989. Publication CDC 89-8411.

2. Fisher M. Report of the US Preventive Services Task Force: Guide to Clinical Preventive Services. Baltimore, Md: Williams \& Wilkins, 1989:289-298.
3. Healthy People 2000: National Health Promotion and Disease Prevention Objectives. Washington, DC: US Dept of Health and Human Services, 1991. Publication PHS 91-50212.

4. Goldstein MG, DePue JD, Monroe AD, et al. A population-based survey of physician smoking cessation counseling practices. Prev Med. 1998;27(5 Pt 1):720-729.

5. Thorndike AN, Rigotti NA, Stafford RS, Singer DE. National patterns in the treatment of smokers by physicians. JAMA. 1998;279:604-608.

6. Fiore MC. The new vital sign: assessing and documenting smoking status. JAMA. 1991;266:3183-3184.

7. Kottke TE, Solberg LI. Is it not time to make smoking a vital sign? Mayo Clin Proc. 1995; 70:303-304.

8. Fiore MC, Jorenby DE, Schensky, AE, Smith SS, Bauer RR, Baker TB. Smoking status as the new vital sign: effect on assessment and intervention in patients who smoke. Mayo Clin Proc. 1995;70:209-213.

9. Chang HC, Zimmerman LH, Beck JM. Impact of chart reminders on smoking cessation practices of pulmonary physicians. Am J Respir Crit Care Med. 1995;152:984-987.

10. Ahluwalia JS, Gibson CA, Kenney RE, Wallace DD, Resnicow K. Smoking status as a vital sign. J Gen Intern Med. 1999;14:402-408

11. Andrews JO, Tingen MS, Waller JL, Harper RJ. Provider feedback improves adherence with AHCPR Smoking Cessation Guideline. Prev Med. 2001;33:415-421

12. Robinson MD, Laurent SL, Little JM Jr. Including smoking status as a new vital sign: it works! J Fam Pract. 1995;40:556-561

13. Ellerbeck EF, Ahluwalia JS, Jolicoeur DG, Gladden J, Mosier MC. Direct observation of smoking cessation activities in primary care practice. J Fam Pract. 2001;50:688-693

14. Mcllvain HE, Crabtree BF, Backer EL, Turner PD. Use of office-based smoking cessation activities in family practices. J Fam Pract. 2000;49: 1025-1029

15. Centers for Disease Control and Prevention. Physician and other health care professional counseling of smokers to quit-United States, 1991. MMWR Morb Mortal Wkly Rep. 1993:42:854-857.

16. Sesney JW, Kreher NE, Hickner JM Webb S. Smoking cessation interventions in rural family practices: an UPRNet study. J Fam Pract. 1997:44:578-585.

17. Goldstein MG, Niaura R, Willey-Lessne C, et al. Physicians counseling smokers: a population-based survey of patients' perceptions of health care provider-delivered smoking cessation interventions. Arch Intern Med. 1997;157:1313-1319.

18. Ward J, Sanson-Fisher R. Accuracy of patient recall of opportunistic smoking cessation advice in general practice. Tob Control. 1996;5: 110-113.

19. Solberg LI. Practical implications of recall bias. Tob Control. 1996;5: 95-96.

20. Bero LA, Grilli R, Grimshaw JM, Harvey E, Oxman AD, Thomson MA. Closing the gap between research and practice: an overview of systematic reviews of interventions to promote the implementation of research findings. BMJ. 1998;317:465-468.

21. NHS Centre for Reviews and Dissemination. Getting evidence into practice. Eff Health Care. 1999;5:1-16.

22. Solberg LI. Guideline implementation: what the literature doesn't tell us. Jt Comm J Qual Improv. 2000;26:525-537. 